\title{
YouTube \\ koko kansan oppimisen ja opettamisen areenana
}

\author{
$+y$ \\ Videopalvelu YouTube on täynnä tavallisten \\ suomalaisten omaehtoisesti tuottamia opetuksellisia \\ videoita. Minkälaisia merkityksiä ja motiiveja \\ videoiden tekijät toiminnalleen kertovat?
}

INTERNETISTÄ ON TULLUT koko kansan foorumi, mikä on aikuiskasvatuksen kannalta mielenkiintoista. Internetiä voidaan pitää viihteellisen oppimisen areenana, aikamme kulttuurisena sivistysfoorumina. Tässä kirjoituksessa keskitymme verkkomedian yhteen mielenkiintoisimmista ilmiöistä, YouTubeen, ja sen suomalaisiin aikuiskäyttäjiin. Googlen omistaman videopalvelu YouTuben tarina alkaa vuodesta 2005. Lyhyeen historiaansa nähden se on kehittynyt merkittävällä tavalla globaaliksi mediailmiöksi: YouTubeen ladataan joka minuutti 300 tuntia videosisältöä (YouTube 2015).

Aikamme digitaalisessa kulttuurissa on ominaista käyttäjien itsensä tuottama sisältö - puhutaankin käyttäjälähtöisestä kulttuurista. Tästä erityisesti internetiin liittyvästä piirteestä on käyty keskustelua sosiaalisen median aikakaudella. Tim O’Reilly ja hänen kollegansa (2005) toteavat, että internetin toiminnot ja sovellukset mahdollistavat helppoja ja halpoja tapoja tuottaa materiaalia verkkoon, mikä on muuttanut internetiä. Olemme sosiaalisia olentoja, haluamme jakaa näkemyksiämme, kokemuksiamme, osaamistamme ja tietoamme toisille ihmisille. Sosiaalisen luonteen lisäksi internetiä ylistetään luovuuden areenana (Gauntlett 2011; Palfrey \& Gasser 2008).

Alan tutkijoita kiinnostaa tällä hetkellä erilaiset verkkotoimijuuden muodot (erityisesti koskien lapsia ja nuoria) sekä digitaalisen kulttuurin kehittyminen ja kulttuurissa eläminen. Vielä ei kuitenkaan tiedetä paljoakaan esimerkiksi verkon aikuiskäyttäjien omista kokemuksista tuottaa sisältöä. Onko kyse altruistisesta jakamisen halusta vai narsistisesta tarpees- 
ta tuoda itseään esille tullakseen huomatuksi, ehkä jopa kuuluisaksi? Voi myös olla, että nämä sisällöntuottajat eivät ole tulleet tarkemmin ajatelleeksi, mikä saa heidät liikkeelle. He ehkä vain tekevät niin, koska se on mahdollista ja helppoa, tai kenties yksinkertaisesti vain hauskaa.

Kiinnostuksemme YouTubeen ja omaehtoiseen videotuottamiseen juontaa juurensa aiemmista tutkimuksistamme, joissa aiheena on ollut omaehtoinen mediatuottaminen ja medialukutaidon mahdollinen muuttuminen verkon ja sosiaalisen median muutosten myötä (ks. esim. Kynäslahti ym. 2008; Sintonen ym. 2014). Minkälaisia tausta-ajatuksia ja intressejä on suomalaisilla henkilöillä, jotka omaehtoisesti tuottavat videoita YouTubeen? Minkälaisia ovat sosiaaliseen mediaan liittyvät mahdolliset pedagogiset aspektit, tietoiset tai tiedostamattomat? Keskitymme tässä kirjoituksessa erityisesti sellaiseen videotuottamiseen, jossa videoiden tekemistä ja niiden sisältöä voidaan luonnehtia ja tarkastella opetuksellisesta, erityisesti toisten opettamisen, näkökulmasta. YouTube on laajalti käytetty ja videotallennepalveluista tunnetuin, joten sen käyttäjien tutkiminen oli luontevaa.

\section{PEDAGOGISEN TUOTTAMISEN, JAKAMISEN JA OSALLISUUDEN NÄKÖKULMA MEDIASIVISTYKSEEN}

Sivistys-käsite on merkityssisällöltään laaja ja kattava (Kokko 2015). Kokon mukaan käsitteen merkitykselliseen kehittymiseen suomen kielessä on vaikuttanut sen historia (määrittelyä ei aikoinaan ole käyty suomeksi) ja hegeliläinen ajattelu, jossa yksilön ja kollektiivisen välinen erittely ei ollut spesifiä. Tänä päivänä sivistyksestä puhutaan muun muassa mediakasvatuksen yhteydessä (ks. esim. Merilampi 2012), mutta sanan käyttö on yhtä laveaa kuin sen käyttö ylipäätään. Tässä yhteydessä mediasivistyksellä viittaamme osaamiseen ja oppineisuuteen mediasta (kulttuurina) ja mediaa kohtaan sekä mediasisältöjen vastaanottajana että tuottajana.

Sivistyksen ja viihteen suhde on toisinaan haasteellinen. Edelleen esimerkiksi kysytään, "katoaako sivistys, kun viihde jyllää päälle?”1. Verkon ja digitaalisen kulttuurin kehittymisen myötä mediasisällöissä voi nähdä viihteellisyyden lisääntymistä aina 1990-luvul- ta alkaen. Populaarikulttuurista, mainoksista ja peleistä on tullut entistä tärkeämpi osa ihmisten elämää. Samaan aikaan koulutus ja kasvatus ovat myös saaneet lisääntyvässä määrin jalansijaa verkossa, ja narratiivisia ja pelillisiä formaatteja tuotetaan myös koulutukselliseen ja opetuksen käyttöön. Edutainment (education + entertainment) kuvaa pyrkimyksiä yhdistää pelaamisen tunne ja koulutukselliset tavoitteet.

On esitetty myös kritiikkiä (mm. Okan 2003; McKenzie 2003) kysymällä, miksi opiskelun pitäisi aina olla hauskaa ja seikkailullista. Voiko asioita oppia ilman vakavaa työskentelyä ja opiskeluponnisteluja? Siinä missä edutainment pyrkii kuvaamaan uusia vaatimuksia institutionaalista koulutusta ja tavanomaista oppimateriaalia kohtaan, olemme kuvanneet omaehtoisen verkossa opettamisen yksilötasoa pedagogisen viihdyttäjän käsitteellä (Sintonen ym. 2012). Pedagoginen viihdyttää on itsenäinen sisällöntuottaja, joka tekee ja julkaisee itse tuottamiaan videoita tutoriaalis-pedagogisesta näkökulmasta ilman kaupallisen hyödyn tavoitetta, jakamisen ja populaarikulttuurin hengessä.

Verkon muuttunut luonne sekä tieto- ja viestintätekniikan kehitys ovat herättäneet keskustelua mediasivistyksen ja -kasvatuksen muutoksista. Useampikin mediakasvatuksen tutkija on nostanut esille uudet medialukutaidot (esim. Knobel \& Lankshear 2006; Kupiainen \& Sintonen 2009). Toteutimme muutama vuosi sitten tutkimuksen, jossa tutkittiin Web2.0:n ja sosiaalisen median mahdollisesti tuomia uusia vaatimuksia medialukutaidolle (Kynäslahti ym. 2008). Tutkimuksen tuloksena oli, että medialukutaito on kulkemassa kohti omaehtoisuutta. Verkon toimintoihin osallistuminen edellyttää yksilöltä halukkuutta: internetiä ei käytetä pelkästään omiin tarpeisiin, vaan myös oman kontribuution jakamiseen toisten kanssa. Tämä halukkuus voi liittyä motivaatioon jakaa omaa asiantuntemusta mahdolliseksi hyödyksi muille. Onko tämä osa nykyajan mediasivistystä? Tuleeko jokaisen ymmärtää omat mahdollisuutensa ja oma roolinsa koko kansan - tai ainakin joidenkin samasta aiheesta kiinnostuneiden - ohjaamisessa, sivistämisessä?

Nykyverkossa painottuu toimintojen vuorovaikutteinen ja sosiaalinen luonne. Parviäly viittaa 
kollektiivisiin toimintoihin merkitysten ja tiedon luomisessa. On kyse jakamisen ja osallisuuden kulttuurista. Internetissä tällainen yhteistyö on mahdollista niinkin, että yhteistyökumppaneiden todellinen identiteetti ei ole selvillä. Anonymiteetti ja henkilökohtaisuus koskevat myös sisällöntuottajaa itseään. Osallistumalla yhteisiin toimintoihin hän tulee paljastaneeksi itsensä muille, oikealla nimellään tai nimimerkillä. Internetille on myös ominaista, että se toimii tavanomaisten tiedonjulkaisukanavien, kuten kustantamoiden, sanomalehtien ja TV-yhtiöiden, ulkopuolella. Tavalliset nettikäyttäjät julkaisevat sisältöä vapaaehtoisesti, kollektiivisesti tai henkilökohtaisesti. The authority of knowledge, tiedon auktoriteetti, on niillä, jotka tuottavat ja julkaisevat sitä ja myös niillä, jotka lisäävät tiedon todenperäisyyttä ja uskottavuutta mm. kommentoimalla ja antamalla sisällöntuottajalle palautetta. Tällainen toiminta edellyttää materiaalin tuottamisen taitoja ja eettisten kysymysten pohdintaa. Tuottajan pitää olla tietoinen vastuustaan sisällöstä toisia käyttäjiä, esimerkiksi lapsia, kohtaan.

Sisällöntuottaminen YouTubeen merkitsee, että tuotos on yhteisöllinen, vaikka lähtökohtana on oma halu tuottaa ja jakaa itse tehtyä materiaalia.YouTubea tutkineiden mukaan se tulisi määritellä sekä palveluksi, alustaksi että yhteisöksi (Burges \& Green 2009; Strangelove 2010).

Omaehtoinen videotuottaminen ja erityisesti itse tuotetun opetuksellisen videomateriaalin jakaminen internetissä liittyy haluun kertoa ja jakaa, vinkata toisille omaa osaamista ja tietoa. Mielenkiintoista on, mikä sisällöntuottajia heidän oman kertomansa mukaan siihen motivoi ja millaisina "pedagogeina" he itsensä mieltävät.

\section{VIDEOTUOTTAJIEN MOTIIVIT OPETUSVIDEOIDEN JULKAISEMISELLE}

Kiinnostuimme tavallisten suomalaisten henkilöiden sellaisten YouTube-videoiden tuottamisesta, joilla oli opetuksellista sisältöä, useita vuosia sitten. Haastattelimme heitä vuonna 2011 ja olemme seuranneet heidän YouTube-tiliensä kehitystä tähän päivään saakka.

Tarkoituksemme on seuraavaksi hahmottaa YouTubesta löytyvää, suomalaisten aikuisten tuot- tamaa opetuksellista videomateriaalia, sekä näiden materiaalien tekijöiden halua laatia opetuksellista, pedagogista sisältöä verkkoon. Selvitimme, miksi ihmiset julkaisevat videoita, joissa he opettavat joitain taitoja tai tietoja toisille. Onko kyseessä hetken kokeilu vai jatkuvaluonteinen toiminta? Miten tekijät itse kuvaavat toimintaansa ja kokevat sen? Ovatko videotuottajat tietoisia videoidensa pedagogisesta luonteesta - yrittävätkö he tietoisesti opettaa, vai mistä on kyse?

Selvitimme näitä kysymyksiä neljän haastattelun avulla. Kaksi haastateltavista oli perustanut YouTubeen tilinsä vuosien 2006-2007 aikana, kaksi vuonna 2010. Syksyllä 2011 kunkin videotekijän omalta kanavalta löytyi muutamia itsetuotettuja ja YouTubeen ladattuja suomenkielisiä videoita. Yhdellä oli myös osa materiaalista englanniksi. Videotuottajien aiheet liittyivät meikkaamiseen ja kauneudenhoitoon, musiikintekemiseen, eräretkeilyyn ja autonkorjaamiseen. Kokonaislatauskerrat vaihtelivat muutamasta sadasta kahteenkymmeneen tuhanteen.

Haastattelujemme perusteella nimesimme pääteemat seuraavasti: oma kokemus, huvi, ei missiota, yksityisyys ja omaehtoisuus. Lisäksi palasimme neljä vuotta myöhemmin haastattelemiimme henkilöihin tarkastelemalla, mitä heidän kunkin YouTube -kanavalle tänä päivänä kuuluu ja kuinka heidän videotuotantonsa on jatkunut.

\section{Oma kokemus}

Haastatelluilla oli omakohtaista kokemusta erilaisten asioiden oppimisesta videoiden välityksellä. YouTubeen sisältyvä oppimiseen liittyvä potentiaali oli tullut tutuksi jo ennen oman videotuotannon aloittamista.

\section{"Olen oppinut tutoriaaleista ihan valtavasti."}

Käsitys siitä, mitä tutoriaali on ja miten hyvä tutoriaali rakennetaan on muodostunut toisten tuottamia videoita katsomalla. Yhden haastateltavan mukaan paras tutoriaali on:

\section{"Simppeli, lyhyt, viihdyttävä ja opettavainen."}

Myös muuhun internetin sisältöön liittyen haastateltavat olivat saaneet ajatuksia omien videoiden 
tuottamisen mahdollisuudesta. Yksi haastateltavista mainitsi asiasta erityisesti oppimisen näkökulmasta:

"Samat kysymykset toistuivat usein foorumilla [mitä seuraa], toisin sanoen oppimisen janoa tuntuu ihmisillä riittävän."

Kaikki haastateltavat totesivat, että videoita on helppo tehdä itse:

"Teknologia tutoriaalien tuottamiseen on käsillä automaattisesti."

Oman tuotannon kehittyessä lisäpontta toiminnan jatkamiselle on saanut katsojilta:

"Jotkut on joskus kysyny neuvoja videoiden tekemiseen."

Kaikki haastateltavat olivat siten ensin itse löytäneet YouTubesta itselleen merkityksellistä, omaa oppimista ja erilaisten taitojen kehittymistä tukevaa materiaalia, jota he olivat hyödyntäneet itseohjautuvasti. Kukaan haastateltavista ei maininnut aloittamisen motiiviksi kavereiden houkuttelua tai kaupallista tavoitetta.

\section{Huvi}

YouTube on viihteellinen ympäristö, mikä näkyi haastateltavien käyttämissä ilmaisuissa. Motiivi omaehtoiseen videotuotantoon vaikutti löytyvän omasta halusta tehdä asiaa, jonka äärellä itse viihtyy.

"Tää on mulle huvi ja harrastus."

"Olen tehnyt pientä listaa tulevien videoiden aiheista ja niistä sitten valitsen sen mikä sillä hetkellä huvittaa tehdä."

Vaikuttaa siltä, että "tilaisuus tekee opettajan". Haastatellut kokivat videon teon ja sen julkaisemisen miellyttäväksi toiminnaksi, jota voi luonnehtia huviksi: tekijä viihdyttää itseään ja muita pedagogisella sisällöllään. Hän on siinä mielessä pedagoginen viihdyttäjä (ks. Sintonen ym. 2012). Pelkästä viihdyttämisestä asian erottaa haastateltavien selkeä käsitys siitä, mihin tarkoitukseen opetuksellista sisältöä tehdään:

"Ihmiset kattoo tutoriaaleja, että ne oppisivat."

Yksi haastateltavista oli aloittanut oman videotuotantonsa kuvaamalla videoita lähinnä itseään varten, muistaakseen parhaimpia juttujaan ja vinkkejään. Hän käytti YouTube -kanavaansa alunperin osin arkistotarkoituksissa.

"Yleensä videoinnin tarkoituksena on ikuistaa asia itselle arkistoon, mutta joskus joku juttu tulee julkaistuakin."

\section{Ei missiota}

Haastatteluista kävi ilmi, etteivät videotuottajat olleet valistuksellisella tai aatteellisella asialla. He eivät julistaneet tai halunneet tietoisesti vaikuttaa muiden käyttäytymiseen. Ennemminkin oli kyse halusta jakaa omaa tietämystään ja osaamistaan. Siihen oli myös ulkoisia vaikuttimia. Yleisön reaktioilla oli merkitystä toiminnan jatkamiselle:

"Kun huomaa, että ihmiset kommentoi ja pyytää, että tee lisää, se on palkitsevaa."

Vähitellen, kun tekijöiden videot olivat alkaneet saavuttaa yleisöä, kiinnostus tuotannon jatkamiseen lisääntyi. Yksi haastateltavista kertoi kyselevänsä videoidensa katsojilta ja kavereiltaan ideoita uusiin aiheisiin:

"Parhaat vaikutteet saa kun opiskelee aiheen itse."

Haastatteluista sai kuvan, että kaikille tuottajille videoiden (jatkuva) tekeminen ja uusien aiheiden löytäminen ei ollut haastavaa:

"Niitä aiheita tulee vain mieleen. Videoni ovat melko helpohkoja aiheeltaan."

\section{Yksityisyys}

Videotuottajien näkemyksissä omasta yksityisyydestään tuli esiin yllättäviäkin piirteitä. Haastattelujen perusteella videoissa esiintyminen haluttiin pääasiassa pitää omana asiana, eikä omaa identiteettiä paljasteta.

"Mielestäni ventovieraitten ei tarvitse tietää toimistani ja ympäristöstäni kaikkea - eikä ne tiedot ole oleellisia aiheissani."

"Suurin osa sukulaisista ja ystävistäni tietävät jotta videoita tulee joskus tehtyä nettiinkin." 
Videoiden tekemistä ei salailtu lähipiiriltä, paitsi yhden kohdalla.

"En koe tarpeelliseksi mainita sitä [videoiden julkaisemista] muille, edes puolisoniei asiasta tiedä ... Ja tietenkin läheisten kommentit satuttavat eniten."

Haastateltavat halusivat toisaalta tuoda omaa osaamista ja tietämystä esille ja muiden käyttöön. Samalla he olettivat ja toivoivat, että oma yksityisyys säilyy. Yllä esitetyissä lainauksissa näkyy eräänlainen "tää on mun oma juttu" -ajattelu. Se ilmentää tietynlaista verkkoidentiteettiä, joka ei kuulu tekijänsä jokapäiväisiin reaalimaailman sosiaalisiin verkostoihin ja perhe-elämään.

"Ensimmäisen oman videoni latasin palveluun muutama kuukausi liittymisen jälkeen - toki olihan siinä melkoinen kynnys julkaista jotain omaa tuotantoa, ja varjelin tosissani jottei vain lipsahtaisi omaa puhetta sekaan, eli koetin (ja koetan vieläkin) säilyttää yksityisyyteni noissa videoissa."

Huolimatta anonyymistä esiintymisestä, kommentointi videoiden ympärillä on suhteellisen vilkasta. Kommentointiin, saamaansa palautteeseen ja myös videoiden latausmääriin haastateltavat suhtautuivat tässä tutkimuksessa hyvin ongelmattomasti. Yleisön saavuttaminen ei aineiston mukaan ole videotuotannon pääasiallinen motiivi.

"Palaute päallisin puolin positiivista, joitain poikkeuksiakin löytyy."

"Palautetta ei ihme kyllä ole kovin paljoa tullut YouTube-palvelussa lienee yhden käden sormilla laskettavissa kommentit."

"Joskus aniharvoin tulee vilkaistua tilastoja. Eipä siitä oikeastaan sen kummempaa merkitystä ole, hyvä jos jotakuta kiinnostaa."

\section{Omaehtoisuus}

Omaehtoisuuden näkökulma on hieman ristiriidassa edellä mainitun yksityisyyden varjelun kanssa. Videotuottajilla oli halua tuoda omaa taitoaan ja tietoaan esiin, ja samalla implisiittisesti omaa itseään.
"En osallistu mihinkään keskusteluihin, lähettele viestejä, yritä verkostoitua tms. Käytän YouTubea pelkästään videoideni esittämiseen."

Kaikissa videoissa oli kyseessä tekijänsä harrastus. Voi myös sanoa, että he olivat harrastuksessaan pitkällä ja sikäli heillä oli annettavaa saman kiinnostuksen kohteen jakaville, kenties siinä taitamattomammille YouTuben käyttäjille. Harrastuneisuus olikin yksi keskeinen omaehtoisuuden piirre.

"Aihetta en sen kummemmin suunnittele, lähinnä arkipäivän ongelmista nuo videotkin hersyvät. Ehkäpä aihe on joko itselleni mielenkiintoinen ja/tai just siitä aiheesta ei ole netistä löytynyt tietoa."

Edellä mainittu ei kuitenkaan tarkoita, että videotuottajat olisivat kokeneet olevansa täysin oppineita alallaan. Palautetta käytettiin opiksi. He myös näkivät oman kehityskaarensa videoiden tuottamisen myötä jo pidemmältä ajalta.

"Mulla on tuo on aika tiukka kohderyhmä ja katsojat tuntuvat löytävän nuo videot ilman mainostamista."

Osa videotuottajista oli löytänyt YouTubesta selkeästi oman paikkansa omalle videotuotannolleen.

\section{Nykytilanne}

Haastatellut neljä videotuottaja-aikuista ovat jokainen alunperin jakaneet videoita omista lähtökohdistaan ja omaan silloiseen elämäntilanteeseensa sopivalla tavalla. On mielenkiintoista tarkastella, mitä heidän YouTube-videotuottamiselle kuuluu tänä päivänä.

Yksi haastatelluista on lopettanut videotuotannon kokonaan ja hän on poistanut kaikki itse tekemänsä videot kanavaltaan, jonka on kuitenkin vielä säilyttänyt. Samalla nimimerkillä löytyy hahmo Instagramista ja Twitteristä (ei kuitenkaan YouTubesta linkitettynä), mutta tekijä ei niissäkään toimi aktiivisesti.

Kaikilla muilla kolmella haastatellulla YouTubeosallistuminen on edelleen aktiivista. He näyttävät edelleen tuottavan omaa sisältöä palveluun ja ovat ladanneet viimeisimmät omat videonsa muutama kuukausi sitten. Heillä kaikilla videoiden aiheet liit- 
tyvät edelleen samoihin alkuperäisiin mielenkiinnon kohteisiin.

Yksi heistä linkittää itsensä ja tuotantonsa kanavallaan Facebookiin, Twitteriin, SoundCloudiin ja Google+ -palveluun, ja hän onkin saanut videoilleen katsomiskertoja lähes kaksi miljoonaa. Kahdella muulla, jotka eivät sinänsä mainosta itseään muissa sosiaalisen median kanavissa, videoiden näyttökerrat ovat parinsadantuhannen luokkaa. Mielenkiintoinen havainto on, että yksi haastatelluista on vaihtanut esiintymisensä anonyymistä tunnistettavaksi (eli hän esiintyy kanavallaan ja videoilla nimellään ja kasvoillaan) ja vinkkaa katsojan YouTube -kanavalla kotisivulleen, mistä löytyy lisää tietoa tekijästä ja hänen taustoistaan. Nähtävästi vuosien kokemuksen myötä rohkeus tulla esiin omana itsenään on lisääntynyt, mutta internetin käyttämisen muoto on pysynyt sosiaalisen median laajempaa käyttöä perinteisempänä verkkojulkaisemisena.

\section{LOPUKSI}

Kuten Eriksson $(2013,199)$ toteaa, verkko on eräs informaalin oppimisen väylä, jossa voidaan esimerkiksi antaa myönteisiä neuvoja ja ohjeita, tai tukea emotionaalisesti vaikeaksi koetussa tilanteessa olevia. Olemme tarkastelleet tässä asiaa opettamisen näkökulmasta. Meitä on kiinnostanut opettaminen ilmiönä, jossa opettajan roolin voi ottaa kuka tahansa.

Mediasivistyksen näkökulmasta tarkasteltuna YouTube on vaikuttava osa aikamme kulttuuria. Se on maailmanlaajuinen media, joka on liikkuvalle kuvalle, äänelle, tekstille ja näiden erilaisille yhdistelmille perustuva palvelu. Sumiala ja Tikka $(2013,180)$ luonnehtivat YouTuben olevan jatkuvassa liikkeessä ihmisten ladatessa ja poistaessa sisältöjä. Tyypillistä on, että koska kuka tahansa voi ladata sisältöä, korostuu horisontaalinen ja ei-hierarkkinen vuorovaikutus ja dialogisuus. YouTube rakentuu sisällöltään sellaiseksi, millaiseksi käyttäjät sen rakentavat:

Amateur videos are not simply representational practices. They are communicative, dialogic events that can provide the basis for community formation. As the foundation of this culture is the production of digital words and moving images, the nature of the- se digital bits will influence the nature of the culture. (Strangelove 2010, 185.)

Keenin (2007) mukaan internet ei edesauta luovuutta, vaan se pikemminkin tuottaa loputonta keskinkertaisuutta. Kupiaisen (2013) mukaan kysymys on lopulta kuitenkin siitä, ymmärretäänkö luovuus ja käyttäjälähtöinen kulttuuri mestariteosten tuottamisen ja julkaisemisen paikkana vai pikemminkin maanläheisemmin mahdollisuutena saada oma ääni esiin ja osallistua kulttuuriseen merkityksenvaihtoon. Hän jatkaa, että tässä mielessä osallisuus ja aktiivinen toiminta ovat jo itsessään positiivisia ilmiöitä.

Aikuiset videotekijät ovat omaehtoisesti liikkeellä ja ottaneet toimijan roolin internetissä. He jakavat sitä, minkä itse kokevat jakamisen arvoiseksi sisällöksi. Internetin asiallisen käyttämisen korostaminen ja sen potentiaalin ymmärtäminen onkin myös aikuiskasvatuksellinen kysymys ja tehtävä: toimijat eivät automaattisesti omaksu digitaalisen kansalaisen ja mediasivistäjän roolia. Se edellyttää tutustumista internetin mahdollisuuksiin, omaa intoa, halua jakaa, välineitä ja riittävää tietotaitoa, joita kaikkia vertaisryhmät ja yhteisöt voivat tukea (vrt. Kupiainen, emt.). Kuten Sumiala ja Tikka (2013, 187-188) toteavat, YouTubella on potentiaali jopa muuttaa ymmärrystämme maailmasta. Halussa opettaa toisia, jakaa ja olla vuorovaikutuksessa on voimaa.

\section{Sara Sintonen}

MuT, dosentti

Opettajankoulutuslaitos

Käyttäytymistieteellinen tiedekunta

Helsingin yliopisto

\section{Olli Vesterinen}

KT

Opettajankoulutuslaitos

Käyttäytymistieteellinen tiedekunta Helsingin yliopisto

Heikki Kynäslahti

KT, dosentti

Opettajankoulutuslaitos

Käyttäytymistieteellinen tiedekunta

Helsingin yliopisto 
Bogdan, R. C. \& Biklen, S. K. (1998). Qualitative Research for Education. An Introduction to Theory and Methods. Third Edition. Boston: Allyn and Bacon.

Burgess, J. \& Green, J. (2009). YouTube. Cambridge: Polity.

Eriksson, I. (2013). Tukea vai ilkeilyä verkkokeskustelupalstalla? Aikuiskasvatus 33 (3), 190-200.

Gauntlett, D. (2011). Making is Connecting. The Social Meaning of Creativity, from DIY and Knitting to YouTube and web 2.0. Cambridge, UK: Polity Press.

Keen, A. (2007). The Cult of the Amateur: How Today's Internet is Killing Our Culture. Garden City, NY: Currency.

Kokko, H. (2015). Sivistyksen varhaista käsitehistoriaa. Kasvatus ja aika 1/2015. http://www.kasvatus-ja-aika. fi/site/?page_id=334 (tarkistettu 7.9.2015)

Kupiainen, R. \& Sintonen, S. (2009). Medialukutaidot, osallisuus, mediakasvatus. Helsinki: Gaudeamus.

Kupiainen, R. (2013). Diginatiivit ja käyttäjälähtöinen kulttuuri. Widescreen 2013/1. http://widerscreen.fi/ numerot/2013-1/diginatiivit/ (tarkistettu 7.9.2015)

Kynäslahti, H., Vesterinen, O., Lipponen, L., VahtivuoriHänninen, S. \& Tella, S. (2008). Towards volitional media literacy through Web 2.0. Educational technology 48(5), 3-9.

Lankshear, C., \& Knobel, M. (2006). New Literacies: Everyday Practices \& Classroom Learning. New York, NY: Open Education Press.

McKenzie, J. (2003). Beyond edutainment and Technotainment. Journal for Quality \& Participation, 26(4), 26-28.

Merilampi, R-S. (2012). Mediasivistystä vahvistamassa - Tietotaitotalkoot pedagogisena mallina. Espoo: Tietotekniikan liitto.

Okan, Z. (2003). Edutainment: is learning at risk? British Journal of Educational Technology, 34(3), 255-264.

0 'Reilly, T. (2005). What is Web 2.0? Design Patterns and Business Models for the Next Generation of Software. 30.9.2005. http://www.oreilly.com/pub/a/ web2/archive/what-is-web-20.html (tarkistettu 7.9.2015)

Palfrey \& Gasser (2008). Born Digital: Understanding the First Generation of Digital Natives. Basic Books. http://pages.uoregon.edu/koopman/courses_ readings/phil123-net/identity/palfrey-gasser_borndigital.pdf (tarkistettu 7.9.2015)

Sintonen, S., Vesterinen, O. \& Kynäslahti, H. \& Mylläri, J. (2012). The lure of creating, producing and sharing of videos on YouTube: a case of a pedagogical entertainer. Proceedings of World Conference on E-Learning in Corporate, Government, Healthcare, and Higher
Education 2012.

Sintonen, S., Kynäslahti, H. \& Kairavuori, S. (2014). Spontaani kuvaviestintä nuorten arjessa. Kasvatus 45(5), 418-428

Strangelove, M. (2010). Watching Youtube: Extraordinary Videos by Ordinary People. Toronto: University of Toronto Press.

Sumiala, J. \& Tikka, M. (2013). Verkko mediaetnografin tutkimuskohteena. Tapauksena uutisen etnografia Youtubessa. Teoksessa Laaksonen, S-M., Matikainen, J. \& Tikka, M. (toim.) Otteita verkosta. Verkon ja sosiaalisen median tutkimusmenetelmät. Tampere: Vastapaino, 170-192.

YouTube. (2015). Tilastotietoa, toukokuu 2015. https:// www.youtube.com/yt/press/fi/

\section{VIITTEET}

1. Tiedeykkönen: Katoaako sivistys ja kuinka käy tieteen, kun viihde jyllää päälle. Radio-ohjelma, Yle: http://areena.yle.fi/1-2684940 